\title{
Seasonal effects on the occurrence of nocturnal leg cramps: a prospective cohort study
}

\author{
Scott R. Garrison MD PhD, Colin R. Dormuth ScD, Richard L. Morrow MA, Greg A. Carney BSc, \\ Karim M. Khan MD PhD
}

Author audio interview: www.cmaj.ca/site/podcasts

See also commentary on page 237 and at www.cmaj.ca/lookup/doi/10.1503/cmaj.150044

Competing interests: Richard Morrow has declared an operational grant to the Therapeutics Initiative's Pharmacoepidemiology Working Group from the British Columbia Ministry of Health. No other competing interests were declared.

This article has been peer reviewed.

Correspondence to: Scott Garrison, scott.garrison@ualberta.ca

CMAJ 2015. DOI:10.1503 /cmaj.140497

\begin{abstract}
Background: It has been anecdotally reported that nocturnal leg cramps in pregnant women are worse in summer. We analyzed population-level data to determine whether the symptom burden of nocturnal leg cramps is seasonal in the general population.
\end{abstract}

Methods: We examined time-series data for 2 independent measures of the symptom burden of leg cramps: (a) new quinine prescriptions (reflecting new or escalating treatment of leg cramps) from December 2001 to October 2007 among adults aged 50 years and older, which were obtained from linked health care databases that contain the prescribing information for the 4.2 million residents of British Columbia, Canada; and (b) the Internet search volume from February 2004 to March 2012 for the term "leg cramps" (reflecting public interest), which we obtained from Google Trends data and geographically limited to the United States and
Australia. We assessed seasonality by determining how well a least-squares sinusoidal model predicted variability in the outcomes.

Results: New quinine prescriptions and Internet searches related to leg cramps were both seasonal, with highs in mid-summer and lows in mid-winter, and a peak-to-peak variability that was about two-thirds of the mean. Seasonality accounted for $88 \%$ of the observed monthly variability in new quinine prescriptions $(p<0.001)$ and $70 \%$ of the observed variability in Internet searches related to leg cramps $(p<0.001)$.

Interpretation: New quinine prescriptions and Internet searches related to leg cramps were seasonal and roughly doubled between the winter lows and summer highs. Why a disorder of peripheral motor neurons displays such strong seasonality warrants exploration.
$\mathrm{N}$ octurnal leg cramps, or rest cramps, are painful involuntary muscle contractions that typically occur in the legs or feet during prolonged periods of rest and often interrupt sleep. ${ }^{1,2}$ Although it is recognized that these cramps originate within motor neurons, as opposed to the muscles in which the symptoms are experienced, their causal mechanism is unknown.,34

It has been anecdotally reported that rest cramps in pregnant women are worse in summer. ${ }^{5}$ Because the seasonality of rest cramps would come as a surprise to most clinicians, offer new therapeutic options and provide potential insight into the cause, we analyzed populationlevel data to determine whether the symptom burden of leg cramps varies seasonally in the general population.

\section{Methods}

\section{Data sources}

We looked for seasonality in new quinine prescriptions within the provincial prescribing databases of British Columbia, Canada. Quinine use is common in Canada. Because the only indication approved by Health Canada (acute malaria) is uncommon, its use is almost exclusively off label for the prevention of nocturnal leg cramps. ${ }^{6}$ Therefore, new quinine prescriptions are an excellent marker for new or escalating treatment of leg cramps, and we previously used these data to assess the potential cramp-promoting effects of commonly used medications. ${ }^{7}$ We also looked for evidence of seasonality more generally (i.e., all 
forms of leg cramps) by using the Google Trends search engine to look for seasonal variation in the volume of Internet searches for the term "leg cramps." ${ }^{8,9}$ We did not use International Classification of Diseases diagnostic codes to identify patients with leg cramps, because their accuracy for this condition has not been validated (in our experience, the codes used by family physicians for leg cramps vary widely).

\section{Quinine prescription data}

Pharmacists in the province of British Columbia are required to enter all prescriptions dispensed at community pharmacies, independent of payer, into the provincial PharmaNet database. This database contains data on drug use by the 4.2 million residents in the province, with minimal underreporting and misclassification. ${ }^{10,11}$ The database is linkable to data from hospital and physician services and registration data for the publicly funded provincial Medical Services Plan. PharmaNet data, excluding the $4 \%$ of the population who are federally insured (e.g., military personnel, First Nations people and inmates in federal penitentiaries), were available for the period Jan. 1, 1996, to June 23, 2009. We linked these data to hospital, physician services and registration records using encrypted patient identifiers. ${ }^{12}$

On Nov. 30, 2000, quinine (previously available over the counter) became a prescriptiononly drug. To ensure that new quinine prescriptions were not renewals of over-the-counter (previously unrecorded) quinine purchases, we limited our analysis to new prescriptions dispensed at least 1 year after the date that prescriptions for quinine were required (i.e., Dec. 1, 2001). In November 2007, a newspaper article (Vancouver Sun, Nov. 16) and a linked radio broadcast (Almanac, CBC Radio One, Nov. 22), both with provincewide distribution, warned about the health risks of quinine. This resulted in a precipitous drop in quinine use, which stayed suppressed for several months. As a result, we chose Oct. 31, 2007, as the last search date for eligible quinine prescriptions. We excluded quinine renewals from our analysis because the timing of a new prescription was presumed to be more strongly associated with disease activity than prescription renewals, which might be triggered as much by running out of pills as by fluctuations in symptom burden.

To help ensure that patients were prescribed quinine for nocturnal leg cramps, we excluded records with physician diagnostic codes or procedural billing indicating malaria, dialysis or amyotrophic lateral sclerosis. We also limited our analysis to patients aged 50 years or older at the time of prescription, because nocturnal leg cramps are uncommon in younger adults and hence young patients with leg cramps might have a higher proportion of cramp-associated disease (e.g., motor neuron disease, radiculopathy or hereditary cramp syndromes) that would make them atypical. ${ }^{4}$

To ensure that new or temporary residents in the province were not filling renewal prescriptions, which would appear as new prescriptions in the drug database, we required evidence that patients had obtained at least 2 years of medical services in the province before the start of treatment with quinine. We used services rendered rather than registration data to determine whether patients were resident in the province, because individuals beginning to live abroad might not immediately cancel their provincial medical plan coverage.

\section{Internet search data}

The Google Trends search engine provides searchable data from 2004 onward for the frequency with which the public enters specified search terms (www.google.com/trends). ${ }^{8,9}$ Results can be global- or region-specific and are presented on a relative scale according to the proportion of overall searches that the selected term represents. Google Trends data have been used for infectious disease surveillance (influenza, tuberculosis and Lyme disease), for assessment of the effect of tax legislation on queries related to smoking cessation and for establishing a seasonal pattern to mood disorders and restless leg syndrome..$^{813-17}$ Our data, downloaded as a spreadsheet of week-by-week relative search volume, consisted of all Google searches originating from the United States (the largest single geographic region in the database) during the period of available data at the time of our analysis (Feb. 15, 2004, to Mar. 11, 2012). We used the search term "leg cramps," which would require the exact phrase to be present in the search field and can be assumed to pick up the public interest in leg cramps. Unlike quinine use, which would be specific to nocturnal leg cramps, Google Trends data suggest a more general public interest in muscle cramping (e.g., it would also include people interested in sports-related cramping). We repeated the search for Australia (where the seasons are reversed from North America).

\section{Sensitivity analyses}

Our group previously reported that inhaled $\beta$-agonists and diuretics are both associated with an increased likelihood of quinine use. ${ }^{7}$ This is relevant because both of these drug classes can 
also be assumed to have some seasonality in their use. Specifically, use of $\beta$-agonists can be expected to increase in winter, when respiratory infections peak, and use of diuretics can be expected to peak in summer, when patients often mention ankle swelling (unpublished clinical observations). Knowing this, we re-examined the data for quinine use after patients receiving diuretics and inhaled $\beta$-agonists were excluded.

To ensure that seasonality in new prescriptions and Internet searches were not common occurrences, we examined data for other selected drug prescriptions and Internet search queries for which we expected no seasonality. For the prescription data, this included all statins, $\beta$-blockers and calcium-channel blockers, and the most common anticonvulsants (valproate, carbamazepine, lamotrigine, gabapentin, topiramate and pregabalin). For Google Trends data, this included searches for other potentially exacerbating and remitting symptomatic conditions: "back pain," "kidney stone," "acne," "migraine" and "panic attack."

\section{Statistical analysis}

We graphed each of the 2 outcome measures (new quinine prescriptions and Internet search

Table 1: Characteristics of patients who started treatment with quinine during in the period Dec. 1, 2001, to Oct. 31, 2007

\begin{tabular}{|c|c|}
\hline Characteristic & $\begin{array}{c}\text { No. }(\%) \text { of patients* } \\
\quad n=31339\end{array}$ \\
\hline Age, yr, median (IQR) & $69(58-80)$ \\
\hline Female sex & 19244 (61.4) \\
\hline \multicolumn{2}{|l|}{ Prescriber } \\
\hline Family physician & 26963 (86.0) \\
\hline Internal medicine physician & $961 \quad(3.1)$ \\
\hline Vascular surgeon & $206 \quad(0.7)$ \\
\hline Neurologist & $172 \quad(0.5)$ \\
\hline Rheumatologist & $135 \quad(0.4)$ \\
\hline Orthopedic surgeon & $67 \quad(0.2)$ \\
\hline Other or not specified & $2835 \quad(9.0)$ \\
\hline \multicolumn{2}{|l|}{ Health authority region $\neq$} \\
\hline Fraser Health & 9662 (30.8) \\
\hline Vancouver Coastal Health & 7049 (22.5) \\
\hline Interior Health & 6527 (20.8) \\
\hline Island Health & 5811 (18.5) \\
\hline Northern Health & $1680 \quad(5.4)$ \\
\hline Not specified & $610 \quad(1.9)$ \\
\hline \multicolumn{2}{|c|}{$\begin{array}{l}\text { Note: IQR = interquartile range. } \\
* \text { Unless stated otherwise. } \\
\text { fPercentage of population } \geq 50 \text { yr of age by Health authority region: Fraser Health }(32.5 \%) \text {, } \\
\text { Vancouver Coastal Health }(23.2 \%) \text {, Interior Health }(19.0 \%) \text {, Island Health }(19.7 \%) \text { and } \\
\text { Northern Health }(5.6 \%){ }^{18}\end{array}$} \\
\hline
\end{tabular}

volume) as a time series and then fit them, using GraphPad Prism software, to 2 models representing either the null hypothesis (no seasonal variation) or the seasonal hypothesis (the presence of annual cycling in symptom burden of leg cramps). The null hypothesis model was the best-fit straight line between the data points, which accounted for the possibility of a gradual and progressive change over time but no seasonal variation. The seasonal model consisted of the best-fit combination of a straight line and a sinusoid according to the following equation:

Outcome $=$ intercept + slope $\times$ time + amplitude $\times \sin (2 \pi \times$ time/wavelength + phase shift $)$

We then used a sum-of-squares $F$ test to compare the 2 models and calculate a $p$ value for the difference in fit.

\section{Ethics approval}

Ethics approval for the study was obtained from the Clinical Research Ethics Board at the University of British Columbia (UBC CREB no. H11-00670).

\section{Results}

The demographic characteristics of the 31339 patients who started quinine treatment during the study period are shown in Table $1 .{ }^{18}$ Median age of the patients was 69 years (interquartile range 58-80 years), more than half $(61.4 \%)$ were female and nearly all $(86.0 \%)$ were prescribed quinine by their family physician.

The seasonal model was a better fit to the data than the null hypothesis model was $(p<0.001)$ for both new quinine prescriptions and Internet search volume (Figures 1 and 2). Seasonality explained $88 \%$ of the variability in quinine prescriptions $\left(R^{2}=0.88\right)$ and $72 \%$ of the variability in Internet search volume $\left(R^{2}=0.72\right)$. The timing of the seasonal cycle was identical for both outcomes, with the peak of new prescriptions and Internet search volume occurring in midJuly (i.e., mid-summer) and the valley of both outcomes occurring in mid-January (midwinter). Both cycles were 365 days in length (364.7 d [95\% confidence interval (CI) 361.5367.8 ] for quinine prescriptions and $365.1 \mathrm{~d}$ for Internet search volume [95\% CI 363.6-366.6]). The magnitude of the effect on both outcomes was also similar: peak-to-peak differences (summer [high] mean - winter [low] mean) in quinine prescriptions were equivalent to $60.4 \%$ of the mean number of prescriptions, and peak-topeak differences in Internet search volume were equivalent to $73.1 \%$ of the mean cramp-related search volume. There was little change in the 
mean number of quinine prescriptions or Internet search volume over time (i.e., the slope of the linear component of our best-fit model was nearly horizontal).

Neither the proportion of female and male patients nor the average age of the patients displayed any seasonal fluctuation. The proportion of prescriptions written by family physicians was constant throughout the year, and each health authority in which the patients lived (whether in the north or south regions of the province) showed similar seasonal fluctuation in new quinine prescriptions.
Although Google Trends data from Australia were sparser overall than the data from the US (producing a noisier, less smooth curve), the Internet searches for leg cramps displayed a similar annual cycle that was 6 months out of phase with the cycle in the US (i.e., searches for leg cramps peaked in January [summer in Australia] and reached their minimum in July [winter in Australia]) (Figure 3).

Exclusion of patients prescribed diuretics and inhaled $\beta$-agonists did not affect the seasonal pattern, which suggested that seasonal variation in the use of these potentially cramp-

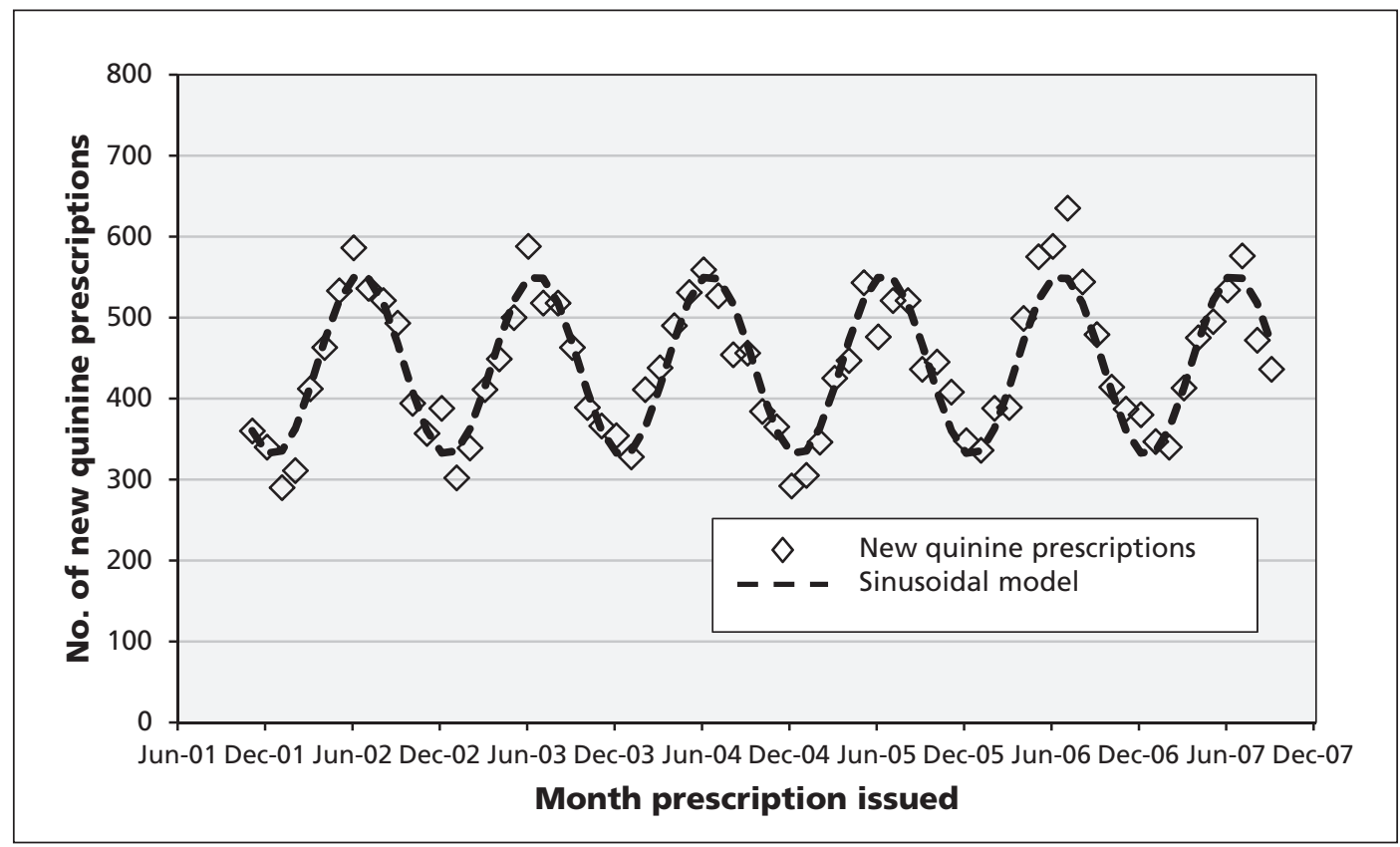

Figure 1: Number of new quinine prescriptions per month for the period Dec. 1, 2001, to Oct. 31, 2007.

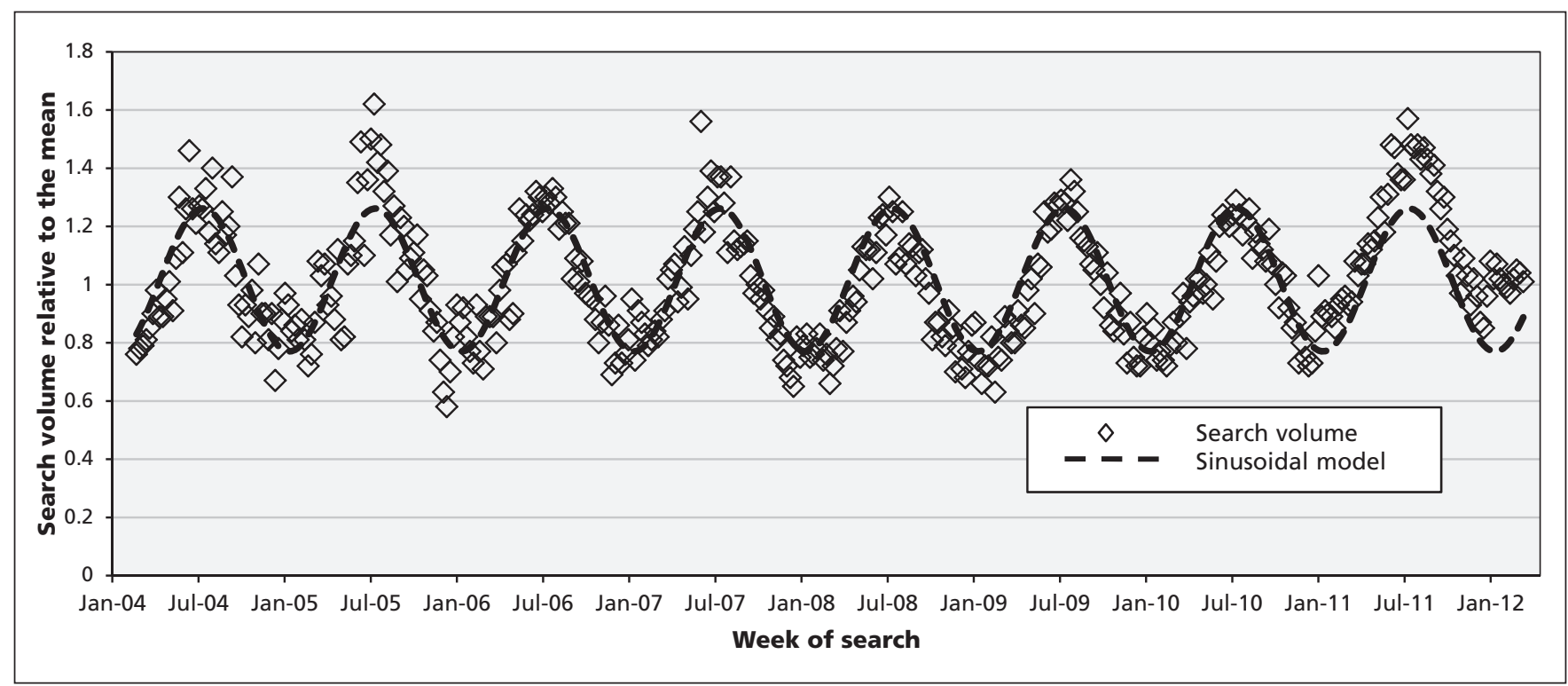

Figure 2: Google Trends Internet search volume relative to the mean for the term "leg cramps" in the United States for the period Feb. 15, 2004, to Mar. 11, 2012. 
promoting medications was not responsible for our findings.

As expected, we found no visible seasonality in the Google Trends searches for back pain, kidney stone, acne, migraine and panic attacks (Appendix 1, available at www.cmaj.ca/lookup /suppl/doi:10.1503/cmaj.140497/-/DC1). For medications for which we expected no seasonal variation in prescriptions, we observed a $10 \%$ $20 \%$ fall in new prescriptions in July through September and again in January and February for more frequently prescribed medications (smoother, less noisy curves) (Appendix 2, available at www.cmaj.ca/lookup/suppl/doi:10.1503 /cmaj.140497/-/DC1). We presume that this was related either to the volume or nature of visits to physicians around holiday periods. Importantly, the summertime fall in these prescriptions was contrary to the observed increase in new quinine prescriptions in the summer months.

\section{Interpretation}

We found that new quinine prescriptions and Internet searches related to leg cramps were highly seasonal and well described by a sinusoid. In regions above (British Columbia and the US) and below (Australia) the equator, the Internet search volume peaked in mid-summer and roughly doubled between the winter lows and summer highs. Although there are anecdotal reports of pregnancy-associated rest cramps being worse in summer, ${ }^{5}$ these findings establish the phenomenon of seasonality in rest cramps in the general population.

\section{Limitations}

One limitation is that individuals who searched Google for information on leg cramps may have done so for a variety of reasons (e.g., cramps associated with age, pregnancy, exercise or neurologic disease). This made it difficult to draw conclusions about any one clinical presentation. However, quinine use in Canada is almost exclusively for the treatment of age-associated nocturnal leg cramps. Therefore, we are confident that this particular cramp syndrome undergoes substantial seasonal cycling. The availability of Google Trends data from Australia (out of phase from the US data by $6 \mathrm{mo}$ ) also helped to confirm a common seasonal rather than calendardriven pattern.

During the selected period of available quinine data, a few drug regulatory bodies (the US Food and Drug Administration [FDA] and its counterparts in Australia and New Zealand) warned against using quinine for the treatment of nocturnal leg cramps based on reports of serious adverse events, most notably thrombocytopenia and cardiac rhythm disturbance. ${ }^{19-21}$ However, none of these warnings appear to have affected quinine use, with the number of dispensed prescriptions per month (renewals and new prescriptions combined) steadily increasing $(2.5$ times) between January 2001 and July 2007 (Appendix 3, available at www.cmaj.ca/lookup

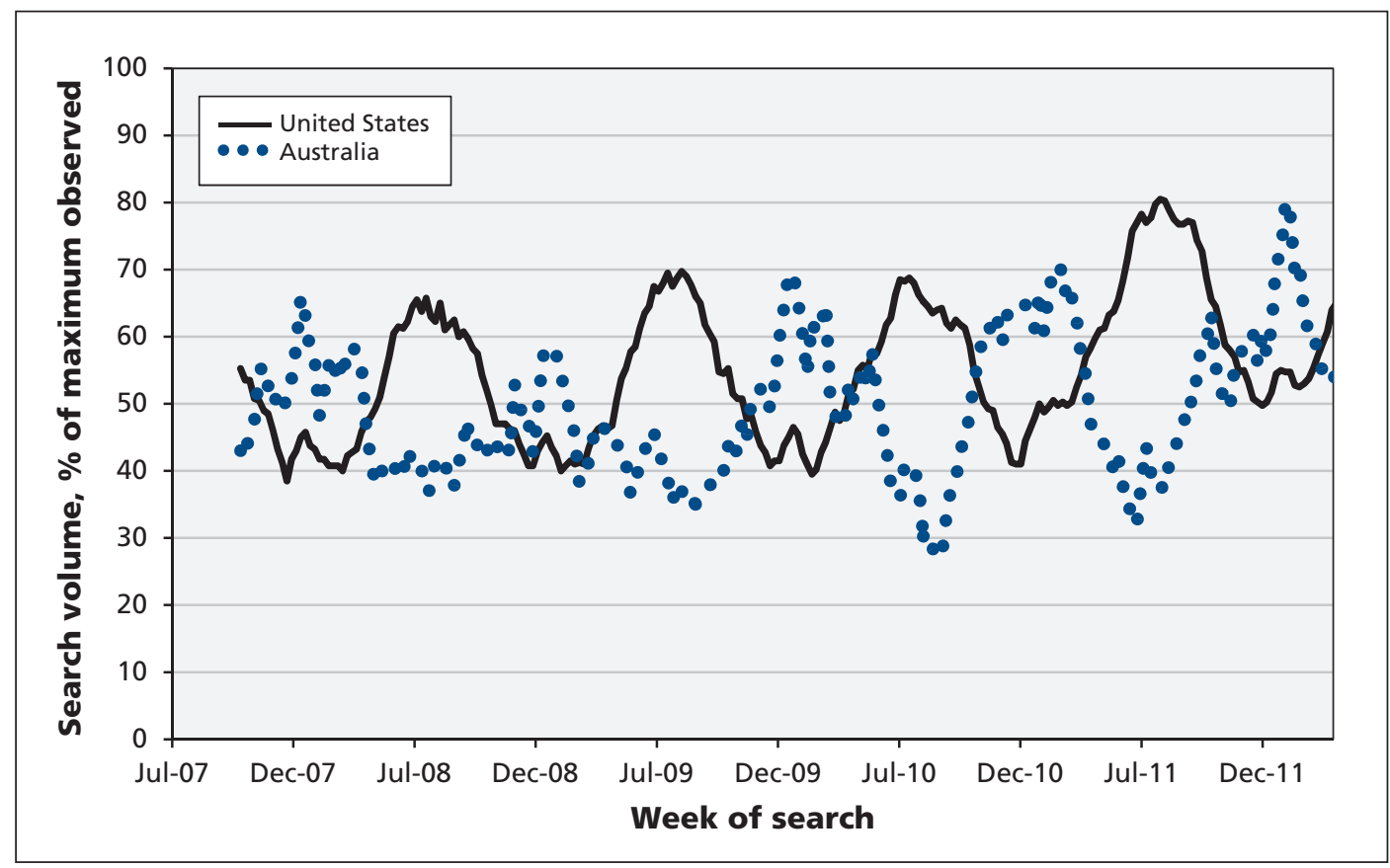

Figure 3: Google Trends Internet search volume as a percentage of the maximum volume observed for the term "leg cramps" in the United States and Australia for the period Sept. 16, 2007, to Apr. 21, 2012. Both lines are 3-week moving averages. 
/suppl/doi:10.1503/cmaj.140497/-/DC1). After the period of available data for quinine use ended in 2009, the FDA enacted a riskmanagement plan in 2010 to warn patients against the use of quinine for leg cramps, ${ }^{22}$ and Health Canada published a warning in the Canadian Adverse Reaction Newsletter in $2011 .{ }^{23} \mathrm{We}$ have no recent data, but our clinical experience suggests that (given there are no alternatives with reasonable evidence of efficacy) off-label quinine use as prophylaxis for rest cramps remains substantial in Canada.

\section{Conclusion}

New quinine prescriptions and Internet searches related to leg cramps were seasonal and roughly doubled between the winter lows and summer highs. Although the mechanism behind the seasonality in leg cramps is unclear, clinicians may wish to inform patients with this condition of the expected fluctuation in their symptoms. In particular, in countries where quinine is still in widespread use as prophylaxis for nocturnal leg cramps despite safety warnings (e.g., Canada and the United Kingdom), physicians may choose to counsel patients to take a "quinine holiday" during the 6 colder months of the year. Moreover, given the seasonal influence on symptoms appears to be greater than the effect of other medical therapies, future trials of medications to treat leg cramps will need to ensure that patient enrolment is balanced with respect to the month of initiation of treatment to control for this potentially confounding effect.

\section{References}

1. Naylor JR, Young JB. A general population survey of rest cramps. Age Ageing 1994;23:418-20.

2. Abdulla AJ, Jones PW, Pearce VR. Leg cramps in the elderly: prevalence, drug and disease associations. Int J Clin Pract 1999; 53:494-6.

3. McGee SR. Muscle cramps. Arch Intern Med 1990;150:511-8

4. Miller TM, Layzer RB. Muscle cramps. Muscle Nerve 2005; 32:431-42.

5. Dahle LO, Berg G, Hammar M, et al. The effect of oral magnesium substitution on pregnancy-induced leg cramps. Am J Obste Gynecol 1995; 173:175-80.

6. Quinine sulfate [product monograph]. In: Compendium of Pharmaceuticals and Specialties [online] (e-CPS). Ottawa: Canadian Pharmacists Association; 2014.

7. Garrison SR, Dormuth CR, Morrow RL, et al. Nocturnal leg cramps and prescription use that precedes them: a sequence symmetry analysis. Arch Intern Med 2012;172:120-6.

8. Seifter A, Schwarzwalder A, Geis K, et al. The utility of "Google Trends" for epidemiological research: Lyme disease as an example. Geospat Health 2010;4:135-7.

9. About Google Trends. Google; 2014. Available: https://support google.com/trends/?hl=en-AU\# (accessed 2014 Nov. 28).

10. PharmaNet. Vancouver: British Columbia Ministry of Health. Available: www.health.gov.bc.ca/pharmacare/pharmanet/netindex html (accessed 2014 Nov. 28).

11. Williams JI, Young W. Inventory of studies on the accuracy of
Canadian health administrative databases. Toronto: Institute for Clinical Evaluative Sciences in Ontario; 1996.

12. Population Data BC. Health care and health services data: Medical Services Plan (MSP) Payment Information File, British Columbia Ministry of Health data extract, 2009. Available: www.popdata .bc.ca/data (accessed 2014 Dec. 8).

13. Ayers JW, Althouse BM, Allem JP, et al. Seasonality in seeking mental health information on Google. Am J Prev Med 2013; 44:520-5.

14. Ayers JW, Ribisl K, Brownstein JS. Using search query surveillance to monitor tax avoidance and smoking cessation following the United States' 2009 "SCHIP" cigarette tax increase. PLoS ONE 2011;6:e16777.

15. Dugas AF, Jalalpour M, Gel Y, et al. Influenza forecasting with Google flu trends. PLoS ONE 2013;8:e56176.

16. Ingram DG, Plante DT. Seasonal trends in restless legs symptomatology: evidence from Internet search query data. Sleep Med 2013;14:1364-8.

17. Zhou X, Ye J, Feng Y. Tuberculosis surveillance by analyzing Google trends. IEEE Trans Biomed Eng 2011;58.

18. BC Stats. 2011 Census profile - British Columbia Health Regions. http://bcstats.gov.bc.ca/StatisticsBySubject/Census /OpenData.aspx.

19. Adverse Drug Reactions Advisory Committee. Quinine and profound thrombocytopenia. Aust Adv Drug Reactions Bull 2002; 21:10.

20. US Food and Drug Administration, Department of Health and Human Services. Drug products containing quinine; enforcement action dates. Fed Regist 2006;71:75557-60.

21. New Zealand Medicines and Medical Devices Safety Authority. Quinine - not for leg cramps anymore. Prescriber Update 2007;28:2-6.

22. FDA Drug Safety Communication: New risk management plan and patient medication guide for Qualaquin (quinine sulfate). Silver Spring (MD): US Food and Drug Administration; 2010. Available: www.fda.gov/Drugs/DrugSafety/PostmarketDrugSafety InformationforPatientsandProviders/ucm 218202.htm (accessed 2014 Nov. 27).

23. Health Canada. Quinine sulphate and serious adverse reactions. Can Adverse React Newsl 2011;21:5.

Affiliations: Faculty of Medicine (Garrison), University of Alberta, Edmonton, Alta; Centre for Hip Health and Mobility (Garrison, Khan), University of British Columbia; Therapeutics Initiative (Dormuth, Morrow, Carney), University of British Columbia; Pharmacology and Therapeutics, Department of Anesthesiology (Dormuth), University of British Columbia, Vancouver, BC; Aspetar Orthopaedic and Sports Medicine Hospital (Khan), Doha, Qatar.

Contributors: Scott Garrison was involved in the study concept and design and drafted the manuscript. Scott Garrison, Richard Morrow and Greg Carney acquired the data. All of the authors were involved in the analysis and interpretation of data, critically reviewed the manuscript, approved the final version submitted for publication and agreed to act as guarantors of the work.

Funding: This study was funded through a general operational grant to the Therapeutics Initiative's Pharmacoepidemiology Working Group, as part of the British Columbia Pharmacovigilance Project (funded by the Government of British Columbia). Scott Garrison was supported through a Doctoral Research Award from the Canadian Institutes of Health Research (CIHR - Institute of Aging). Karim Khan was supported through a CIHR Emerging Team Grant (Mobility in Aging: a Team Approach to Vulnerable Seniors) to the Centre for Hip Health and Mobility at the University of British Columbia, Vancouver.

Acknowledgement: The British Columbia Ministry of Health was a source of data for this study. All inferences, opinions and conclusions drawn in this article are those of the authors and do not necessarily reflect the opinions or policies of the Ministry of Health. 